\section{Koobi Fora hominids}

The Fossil Hominids and an Introduction to Their Context, 1968-1974. (Koobi Fora Research Project, Vol. 1). Edited by M. G. Leakey and R. E. Leakey. Pp. 191. (Clarendon/Oxford University Press: Oxford, 1978.) $£ 15$.

THIS is the initial volume of a projected series of monographs on interdisciplinary earth sciences and palaeoanthropological researches in the Koobi Fora area, northeastern Turkana basin, Kenya. That combined research effort unquestionably represents one of the most lastingly important and fruitful investigations into the earlier evolutionary history of Hominidae and the natural setting and biotic associations of Plio-Pleistocene times. This volume provides an historical and methodological introduction (R. E. Leakey); followed by chapters on geology, palaeontology, archaeology and fossil hominids.

A summary of the lithostratigraphy, sedimentary environments and palaeogeography of the Kubi Algi and Koobi Fora formations is provided by I. C. Findlater. This chapter sets out the stratigraphical nomenclature now used for these formations, the members of which are defined on the basis of several spatially extensive tephra. Five principal sedimentary environments are recognised, two lacustrine and three alluvial; and their areal relationships are shown diagrammatically. Eight generalised maps depict palaeogeographical settings of the area of successive temporal intervals during the accumulation of the Koobi Fora Formation. Maps show the locations of the principal hominid finds in the major fossiliferous areas; their temporal relationships and environments of deposition are indicated in stratigraphical section and usefully summarised in a table.

An annotated inventory (and listing) of 87 mammal taxa (exclusive of micromammals) in those formations, as well as mollusc assemblages and their concurrent range zones, and notes on other vertebrate groups is given by J. M. Harris. The fauna of the Kubi Algi Formation is not specified, but is stated to overlap in part that of the (lower) portion of the Koobi Fora Formation. The Ileret, Koobi Fora and Kubi Algi sectors have been each subdivided into a series of numbered areas (19 in the former two, 5 in the latter) for purposes of geological mapping and fossil collection. Tephra deposits are widespread, some demonstrably spatially extensive and useful in correlation. Certain (named) tuffs serve as marker horizons to differentiate and to subdivide the several formations; however, the relationships, spatially and temporally, of many other (numbered) tuffs are uncertain. Three fossi 'collection units' are now recognised for the Kubi Algi Formation, and five such 'units' for the Koobi Fora Formation, the base of each being defined in a particular area by a named or numbered tuff. However, in the Koobi Fora Formation just over half of all fossiliferous areas in the Ileret sector and nearly half of all such areas in the Koobi Fora sector have lithostatigraphically undefined lower boundaries. Thus, the 'collection unit' concept seems to have limited utility at best, as it is an unfortunate mix of both lithostratigraphy and biostratigraphy.

An overview of the stratigraphical and areal situation, depositional environments and associations, and nature of all major archaeological occurrences, and their content and industrial characteristics is provided by G. L. Isaac and J. W. K. Harris. The remainder of the volume comprises a well-illustrated inventory, with data on finder, provenience and depositional environment (including many microstratigraphic sections) of all fossil hominids (numbering 129) recovered in the seven years of the project, until 1974 (R. E. and M. G. Leakey and A. K. Behrensmeyer), complemented by an appendix of 30 tables of assorted measurements of those specimens. The scale on some hominid illustrations is unfortunately incorrect. Hominid taxonomy is only briefly mentioned (p89); but not many workers personally familiar with this vast corpus of fossil material will agree with all the attributions suggested. Finally, there is a full bibliography (through 1976) of the project.

This is an immensely useful, well executed and well produced volume of major import to all students of human evolution.

\section{F. Clark Howell}

F. Clark Howell is Professor of Anthropology at the University of California at Berkeley.

\section{Coastal sedimentation}

Coastal Sedimentary Environments. Edited by Richard A. Davis, Jr. (Springer: New York and Berlin, 1978.) \$22; DM44.

THIS book is intended as a student text and to provide a background on coastal environments for geologists, engineers, oceanographers and coastal managers. Being a multi-author text means that there are certain differences of approach between the chapters; however, this is offset by the obvious expertise that has been brought to bear. The emphasis is on geological description of the morphological features and of the processes that have been interpreted largely from changes in the morphology and from the analysis of internal structures. The chapters have a review style and frequently, to provide an explanation satisfactory for students, would necessitate lectures tailored to the book, or the student to follow up extensively the quoted papers. An example of this is the very brief coverage of longshore transport, which in itself would warrant a chapter in a more specialist book. The bibliographies are reasonably comprehensive and there are abundant and very good photographs, especially of tidal deltas.
There are chapters on river deltas by L. D. Wright, which particulariy concentrates on the processes in the Mississippi delta, and on coastal bays by R. B. Biggs, which actually emphasises suspended sediment in estuaries. There is a particularly comprehensive description of American East Coast salt marshes by R. W. Frey and P. B. Basan, and coastal dunes are described by V. Goldsmith. R. A. Davis describes the beach and nearshore zone, and mesotidal inlets and estuaries are covered by J. C. Boothroyd. The latter concentrates largely on tidal deltas. The final two chapters are by J. C. Kraft on the coastal stratigraphic sequences produced mainly by transgression, and by W. T. Fox on modelling coastal environments.

Virtually all of the examples quoted are drawn from the American East or Gulf Coasts. Consequently the extensive body of European literature is largely neglected, together with such features as high range tidal estuaries and coasts. Nevertheless, this will be a useful addition to texts on coastal sedimentation and should be recommended reading on courses covering coastal geomorphology and sedimentology, as well as providing useful background in a wider range of disciplines.

K. R. Dyer

$K$. R. Dyer is at the Institute of Oceanographic Sciences, Taunton, UK. 